\title{
Experimental inoculation of gilts with bovine viral diarrhea virus 2 (BVDV- 2) does not induce transplacental infection
}

\author{
Daniele Araujo Pereira ${ }^{\mathrm{a}}$, Juliana Brigolin Peron ${ }^{\mathrm{a}}$, Henrique Meiroz de Souza Almeida ${ }^{\mathrm{a}}$, \\ Thaís Gasparini Baraldi ${ }^{a}$, Igor Renan Honorato Gatto ${ }^{\text {a }}$, Thaiane Coelho Kasmanas ${ }^{\text {a }}$ \\ Edviges Maristela Pituco ${ }^{\mathrm{b}}$, Hélio José Montassier ${ }^{\mathrm{a}}$, Luís Guilherme de Oliveira ${ }^{\mathrm{a}, *}$ \\ ${ }^{a}$ School of Agricultural and Veterinarian Sciences (FCAV), São Paulo State University (Unesp), Via de Acesso Prof. Paulo Donato Castellane s/n, Jaboticabal, SP, 14884- \\ 900, Brazil \\ ${ }^{\mathbf{b}}$ Biological Institute of São Paulo, Av. Conselheiro Rodrigues Alves, 1252 - Vila Mariana, São Paulo, SP, 04014-002, Brazil
}

\section{A R T I C L E I N F O}

\section{Keywords:}

BVDV

Seroconversion

Viremia

qRT-PCR

Pestivirus

\begin{abstract}
A B S T R A C T
Bovine viral diarrhea virus (BVDV) belongs to the genus Pestivirus and can cause reproductive problems in cattle. However, there is still a lack of research to clarify its pathogenicity in different gestational periods of sows and its effects in neonates. In this study, 12 gilts divided into groups (G) were experimentally inoculated with the strain BVDV-2 (SV-253) oronasally at a dose of $10^{6.85}$ TCID50; one group was inoculated 30 days before insemination $(\mathrm{G0} ; \mathrm{n}=2)$, three groups were inoculated during gestation (first $(\mathrm{G} 1 ; n=2)$, second (G2; $n=3$ ), third (G3; $n=3)$ ), and a fourth was the control group ( $G 4 ; n=2)$. Samples of blood and nasal swabs from the gilts were collected every three days until delivery for a virus neutralization (VN) test, qRT-PCR, and blood count. On the day of delivery, $40 \%$ of the neonates were euthanized to obtain tissue and blood samples at necropsy for histopathology and qRT-PCR. The sows were seroconverted between 12 and 33 days after inoculation, and the virus was detected in the blood between 3 and 12 days and on the nasal swab between 6 and 24 days in the G0, G1, G2 and G3 sows but was not detected in piglet tissues, and no significant alterations were found through histopathology. The mean and standard deviation of the mean cycles $(\mathrm{Cq})$ from blood $(\mathrm{Cq}=34.87 \pm 0.60)$ and nasal swab $(\mathrm{Cq}=34.61 \pm 0.87)$ samples were between 107 and $490 \mathrm{TCID} 50 / \mathrm{ml}$. Transient infection was demonstrated with a low viral load, but transplacental infection was not possible in gilts.
\end{abstract}

\section{Introduction}

The genus Pestivirus within the family Flaviviridae has been classified according to the International Committee on Taxonomy of Viruses (ICTV) into $A, B, C, D, E, F, G, H, I, J$ and $K$. Species are designated as Pestivirus $A$ (originally designated Bovine viral diarrhea virus [BVDV] 1), Pestivirus B (BVDV 2), Pestivirus C (Classical swine fever virus [CSFV]), Pestivirus D (Border disease virus [BDV]), Pestivirus E (pronghorn pestivirus), Pestivirus $F$ (Bungowannah virus), Pestivirus $G$ (giraffe pestivirus), Pestivirus $H$ (Hobi-like pestivirus), Pestivirus I (Aydin-like pestivirus), Pestivirus $J$ (rat pestivirus) and Pestivirus $K$ (atypical porcine pestivirus [APPV]) (Smith et al., 2017).

The complete genome of Pestivirus is approximately $12.3-12.7 \mathrm{~kb}$ long and is comprised of a conserved 5' UTR with 360-390 nucleotides (Pellerin et al., 1994). BVDV can also be classified as cytopathic (CP) and noncytopathic (NCP) according to its ability to cause cytopathogenic effects in cell culture. NCP viruses are known to be the majority of field isolates (Dezen et al., 2013). Acute infections with NCP viruses in bovids cause transient viremia with different shedding patterns (Houe, 1995). In addition, transplacental infection can generate persistently infected (PI) calves (Viet et al., 2007).

Pestiviruses were initially classified into BVDV, CSFV and BDV species based on the original host animals, and it was later reported that some pestiviruses do not only infect a single host species (Ridpath, 2010). BVDV has been reported in other animals, such as swine, sheep, goats, deer and wild and domesticated ruminants (Vilcek et al., 2004; Tao et al., 2013; Postel et al., 2016). Pestiviruses have highly variable RNA and cause economically relevant diseases in pigs. In the last two decades, a growing number of new pestiviruses have been discovered in various types of domestic animals (Postel et al., 2016). Moreover, BVDV infections in swine have drawn the attention of veterinarians due to their clinical resemblance to Classical Swine Fever in infected herds (Liess and Moennig, 1990).

The majority of BVDV infections in swine have no clinical signs;

\footnotetext{
* Corresponding author.

E-mail address: luis.guilherme@unesp.br (L.G. de Oliveira).
} 
however, reproductive disorders in sows and the birth of weak piglets, abortion and mummified fetuses have been associated with infection (Vannier and Albina, 1999). In pregnant sows, transplacental infection with BVDV was associated with abortion, stillbirths, birth of weak piglets, fetal malformation and even birth of PI piglets (Becher et al., 2003). A past report of pregnant sows experimentally inoculated with BVDV-1 on the 65th day could not detect vertical transmission (Walz et al., 2004). On the other hand, the effects of infection in other gestational periods have not been investigated. Intrauterine experimental infections were reported to cause reproductive disorders resembling infections caused by low- or average-pathogenicity CSFV (Paton and Done, 1994; Kulcsár et al., 2001). Moreover, BVDV infections in swine can interfere with the surveillance and eradication of CSFV, primarily due to potential serological cross-reaction in diagnostic tests (Pellerin et al., 1994). Since there are few studies regarding the effects of BVDV infection in the swine host, this study focused on clarifying the pathogenicity of BVDV-2 infections in pregnant sows over time with regard to viral replication in the host, humoral immune response and reproductive losses from BVDV-infected gilts.

\section{Materials and methods}

\subsection{Experimental design}

This study was performed at the Faculty of Agricultural and Veterinary Sciences, São Paulo State University (FCAV- UNESP/ Jaboticabal), in partnership with the Biological Institute of São Paulo. This study was composed of 12 gilts divided into five groups that were experimentally inoculated with the strain BVDV-2 (SV-253) during different stages of pregnancy. $\mathrm{G0}(\mathrm{n}=2)$ was inoculated 30 days before insemination, $\mathrm{G} 1(\mathrm{n}=2)$ was inoculated 30 days after insemination, G2 $(\mathrm{n}=3)$ was inoculated 60 days after insemination, G3 $(\mathrm{n}=3)$ was inoculated 90 days after insemination, and G4 $(n=2)$ was mock inoculated. On the day of delivery, $40 \%$ of the neonates of each gilt were evaluated (Fig. 1), including stillbirths and mummies, and neonates were euthanized without colostrum ingestion.

\subsection{Physical examination and differential diagnosis}

Naïve gilts were vermifuged; inseminated; vaccinated against erysipela, parvovirus, and leptospirosis; and evaluated daily, and their temperature was measured every three days until delivery. Previously, gilts were tested for leptospirosis by a microscopic agglutination test and BVDV antibodies by a virus neutralization (VN) test. Cases of abortion during the experiment were tested for circovirosis and parvovirus as differential diagnosis.

\subsection{Sampling}

The samples collected from the sows every 3 days until delivery were blood, blood serum and nasal swabs, and the placenta was collected on the day of delivery; blood and tissues (brain, kidney, lung, thymus, tonsil, small intestine, spleen, liver, mesenteric lymph node) were collected from the piglets. The blood of the gilts was collected by jugular venipuncture and stored in sterile tubes with EDTA (ethylenediamine tetraacetic acid) to obtain whole blood. Serum samples were placed in EDTA-free tubes and stored at $-20^{\circ} \mathrm{C}$. Nasal swabs were collected and suspended in $300 \mu$ l of Eagle's minimal essential medium (EMEM) (LGC Biotechnology, São Paulo). The organ samples were stored in RNase- and DNase-free microtubes, instantly frozen in liquid nitrogen and later kept at $-80{ }^{\circ} \mathrm{C}$. This research was submitted and approved by the CONCEA (National Council of Animal Experimentation Control) and the institution's CEUA (Ethics Commission for Animal Experimentation) under protocol number 5925/15.

\subsection{BVDV inoculum preparation and administration}

The inoculum was composed of BVDV genotype 2 (CP) strain SV253; the bovine isolate was kindly provided by Dr. Eduardo Flores, Department of Virology, Department of Preventive Veterinary Medicine, UFSM, Santa Maria, RS, originating from the University of Nebraska at Lincoln USA, isolated in 1990 by Dr. Rubens Donis (Arenhart et al., 2008). After being thawed at $37^{\circ} \mathrm{C}, 15 \mathrm{ml}$ of the BVDV2 (SV253) 6th Mardin-Darby Bovine Kidney (MDBK) inoculum termed $10^{5.5} \mathrm{TCID} 50 / \mathrm{ml}$ was administered to the gilts at $5 \mathrm{ml}$ in each nostril after local scarification, and $5 \mathrm{ml}$ was administered orally according to the method described by Cabezón et al. (2010).

\subsection{Hemogram}

Whole blood samples were used to assess erythrocyte, leucocyte and thrombocyte counts, as well as hemoglobin concentration and hematimetric indices, such as globular volume, mean corpuscular volume (MCV), mean corpuscular hemoglobin (MCH) and mean corpuscular hemoglobin concentration (MCHC). The total leucocyte count was performed using semiautomatic hematology analyzer (pocH-100iV Diff, Sysmex, Roche Diagnostic, Brazil); blood smears were performed and stained using the Rosenfeld method for leucocyte differential count

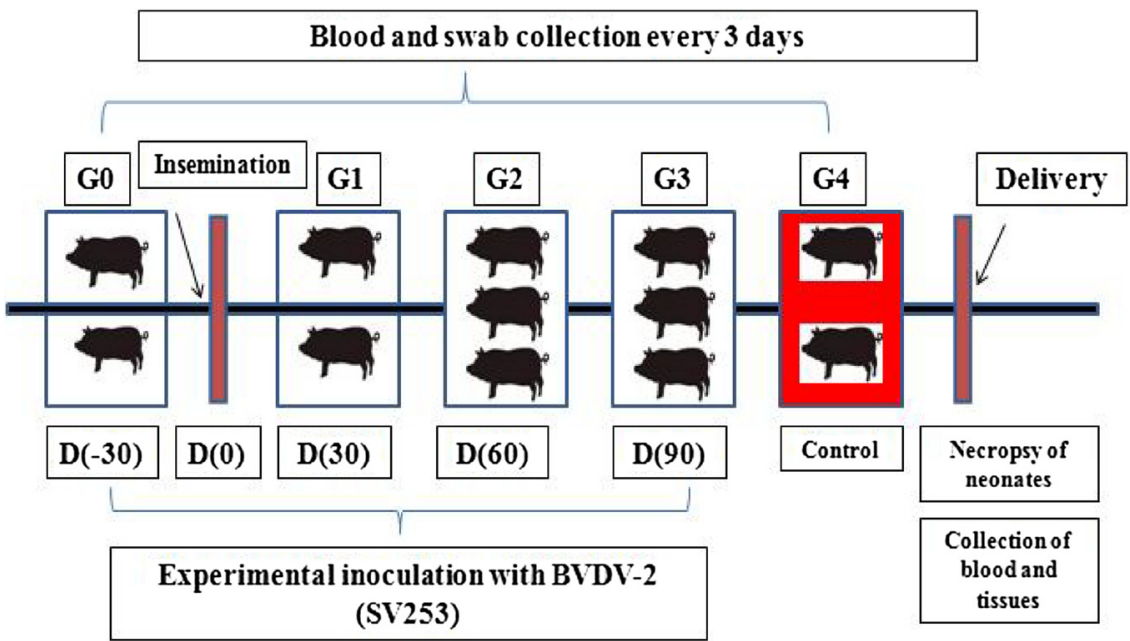

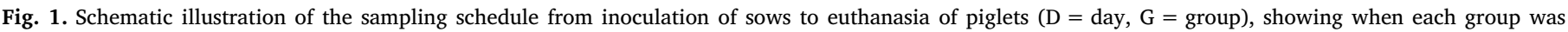
inoculated with BVDV-2 (VS-253), 30 days prior to insemination (G0), and during gestation with 30 (G1), 60 (G2), 90 (G3) days and G4 (Control). 
(Jain, 1986). The animals were evaluated on days $0,3,6,12,18,24$, 27 , and 36 after experimental inoculation and group control.

\subsection{Virus neutralization (VN) assay}

For the VN assay, all serum samples obtained were serially diluted starting at 1:10 through 1:5120. Positive results were characterized by total neutralization of the 100 TCID50 in serum dilutions higher than or equal to 1:10, as preconized by the "Manual of Diagnostic Tests and Vaccines of Terrestrial Animals" with modifications (OIE, 2016). The MDBK cell line was used in the test, and BVDV-2 SV253 (CP) was the standard virus. Antibody titers were expressed by the inverse of the highest dilution in which all of the 100 TCID50 were neutralized, and the final titer between the duplicates was determined by the geometrical mean of both results.

\subsection{Viral RNA extraction}

The total nucleic acids were extracted from whole blood samples using RiboPure ${ }^{\mathrm{TM}}$ RNA Purification Kit (Thermo Fisher Scientific, Austin, TX) according to the manufacturer's instructions. Viral RNA extraction from tissue samples, nasal swabs and positive controls (BVDV) was performed using TRIzol (Thermo Fisher Scientific, CA, USA), according to the manufacturer's instruction with some adjustments. Purification of the extracted RNA was analyzed by spectrophotometer (Nanodrop) to evaluate the qualities of the samples, with $260 / 280$ and $260 / 230$ in combination and overall spectral quality.

\subsection{Detection of the BVDV-2 genome by $q R T-P C R$ and thermal profile}

RNA extracts were tested for the presence of RNA from BVDV by quantitative real-time PCR. Applied Biosystems 7500 Real-Time equipment was used, and the thermal profile of qRT-PCR was according to the manufacturer's recommendations of the VetMAX ${ }^{\mathrm{TM}}$ Gold BVDV Detection Kit (Thermo Fisher Scientific, Austin, TX). The cutoff point was established at $\mathrm{Ct}>38$.

\subsection{Calibration curve}

A serial dilution was made from the initial viral suspension at the dose of $10^{6.85}$ TCID50 to $10^{1.85}$ TCID50. This curve was generated in order to relate the values of $\mathrm{Ct}$ to the amount of virus and was assessed according to a previously published index (Zeitler and Rapp, 2013). Calibration curves were constructed by plotting Cq values on infectious BVDV titers in the serial dilution samples, and each sample was measured in duplicate.

\subsection{Histopathology}

Tissue samples of brain, thymus, lungs, kidney, mesenteric lymph nodes, small intestine, tonsils, liver and spleen from necropsied piglets born from G0, G1, G2, G3 and G4 were cut into $2 \mathrm{~mm}$ slices, fixed in $10 \%$ buffered formalin for $24 \mathrm{~h}$, put in $70 \%$ ethanol and paraffin embedded. The paraffin-embedded tissues were cut and stained with hematoxylin-eosin (HE) and observed under a light microscope.

\section{Results}

\subsection{Physical and clinical assessment of gilts and piglets}

The gilts' temperature remained within the normal range throughout the experiment; only gilt 323 showed a temperature of $40.5^{\circ} \mathrm{C}$ on the day of abortion. After oronasal inoculation with BVDV-2, the G0 sow (323) aborted at 60 days' gestation (fetus was $12 \mathrm{~cm}$ ), and the G2 sow (364) returned to estrus 42 days after insemination. It was observed that one sow from each group produced a stillborn piglet, but only one sow from the experimentally infected group (G3) gave birth to a mummified fetus (Table 3).

\subsection{Hemogram}

Regarding the evaluation of platelets, two sows from group G2 (364, 729) that were inoculated at 60 days presented with thrombocytopenia 36 days after inoculation with BVDV-2, and one G0 sow (392) presented with thrombocytopenia 24 days after the infection. Hemoglobin values and MCHC remained normal. G1 (355) and G2 (729) sows showed below-normal erythrocyte and hematocrit values 36 days after inoculation, but the other animals maintained normal levels every day. With respect to lymphocyte augmentation, six animals showed mild lymphocytosis between 3 and 6 days after inoculation, and the cells returned to normal quickly thereafter; two animals showed an increase in segmented neutrophils at 24,27 , and 36 days after inoculation. No basophils or band cells were detected. The monocyte and eosinophil counts were normal for the species.

\subsection{Virus-neutralizing antibody titers}

Anti-BVDV-neutralizing antibodies were detected in the sows in all experimentally inoculated groups, except in the control (G4) and G3 groups between the 12th and 33rd days postinoculation. G0 seroconversion averaged 20 days, G1 averaged 27 days and G2 averaged 12 days; the overall seroconversion of the three groups was 20 days, with titers ranging from 10 to 160 (Table 1 ). The difference in titers was

Table 1

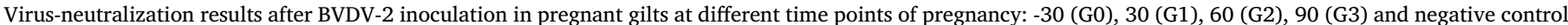
(G4), every three days until the day of delivery $(0,3,6,9,12,15,18,21,24,30,33,36,45,57,60,63)$.

\begin{tabular}{|c|c|c|c|c|c|c|c|c|c|c|c|c|c|c|c|c|c|c|c|}
\hline \multirow[t]{2}{*}{ Group } & \multicolumn{19}{|c|}{ Day } \\
\hline & 0 & 3 & 6 & 9 & 12 & 15 & 18 & 21 & 24 & 27 & 30 & 33 & 36 & 39 & 42 & 45 & 57 & 60 & 63 \\
\hline 323 (G0) & - & - & - & - & - & - & 10 & 10 & 10 & 10 & 20 & 40 & 20 & 20 & 20 & 80 & 160 & 160 & 80 \\
\hline 392 (G0) & - & - & - & - & - & - & - & 10 & 10 & 10 & 10 & 10 & 10 & 10 & 20 & 20 & 80 & 40 & 80 \\
\hline 427 (G1) & - & - & - & - & - & - & - & 10 & 10 & 10 & 10 & 10 & 20 & 10 & 10 & 20 & 40 & 40 & 10 \\
\hline 355 (G1) & - & - & - & - & - & - & - & - & - & - & - & 20 & - & 10 & 10 & 20 & 10 & 40 & 20 \\
\hline 1386 (G2) & - & - & - & - & 10 & 10 & 10 & 10 & 10 & 10 & 10 & 10 & 10 & 10 & 10 & 10 & $\mathrm{~F}$ & & \\
\hline 364 (G2) & - & - & - & - & 10 & 10 & - & 10 & - & 10 & 20 & 10 & 20 & 10 & 20 & 10 & - & & \\
\hline 729 (G2) & - & - & - & - & 10 & - & 10 & - & 10 & 10 & 20 & 10 & 20 & 10 & 10 & - & $\mathrm{F}$ & & \\
\hline 348 (G3) & - & - & - & - & - & - & - & $\mathrm{F}$ & & & & & & & & & & & \\
\hline 363 (G3) & - & - & - & - & - & - & - & $\mathrm{F}$ & & & & & & & & & & & \\
\hline 365 (G3) & - & - & - & - & - & - & - & $\mathrm{F}$ & & & & & & & & & & & \\
\hline 301 (G4) & - & - & - & - & - & - & - & - & - & - & - & - & - & - & - & - & - & - & $\mathrm{F}$ \\
\hline 347 (G4) & - & - & - & - & - & - & - & - & - & - & - & - & - & - & - & - & - & - & $\mathrm{F}$ \\
\hline
\end{tabular}

(-) Absence of titles, F- Farrowing. 
greater in G0 than in G1 and G2. Anti-BVDV antibodies were not detected in the serum of the evaluated piglets born from the sows in all of the infected and control groups.

\subsection{Generation of calibration curves and BVDV quantification in $q R T-P C R$}

Calibration curves were generated using defined amounts of the initial viral suspension of the BVDV strain VS253 in EMEM with $10^{6,85}$ TCID50 $(\mathrm{Cq}=15.239)$ and its dilutions in the samples, $10^{5,85}$ TCID50 $(\mathrm{Cq}=21,886), \quad 10^{4,85} \quad$ TCID50 $\quad(\mathrm{Cq}=26.304), \quad 10^{3,85} \quad$ TCID50 $(\mathrm{Cq}=29.700), \quad 10^{2,85} \quad$ TCID50 $\quad(\mathrm{Cq}=33.004), \quad 10^{1,85} \quad$ TCID50 $(\mathrm{Cq}=34.706)$.

\subsection{Detection of the BVDV genome by $q R T-P C R$ in experimentally inoculated gilts and piglets}

Overall, 452 samples were analyzed, including 130 sow nasal swabs, 150 sow blood samples, 37 piglet blood samples, 11 placenta samples and 124 piglet tissue samples. Viremia (whole blood samples) and viral shedding (nasal swabs) were detected in sows; however, vertical transmission was not detected because all samples from piglets were negative in the qRT-PCR. Viremia was detected in four sows (392, $427,729,348$ ) that belonged to groups G0, G1, G2 and G3, respectively. Viral shedding was also detected in four sows (323, 392 355, 1386) from groups G0, G0, G1 and G2, respectively, and the number of TCID $50 / \mathrm{ml}$ of each animal was demonstrated. The mean and standard deviation were $\mathrm{Cq}=34.87 \pm 0.60$ for blood samples and $\mathrm{Cq}=34.61 \pm 0.87$ for nasal swabs. The lowest Cq value was found in a nasal swab specimen $(\mathrm{Cq}=33.15)$, equivalent to $490 \mathrm{TCID} 50 / \mathrm{ml}$. Transient viremia occurred in sows between three and twelve days, and nasal excretion occurred between six and twenty-four days after viral inoculation, with viral quantification ranging from 107 to 490 TCID50/ $\mathrm{ml}$ (Table 2).

\subsection{Histopathology}

No significant findings were found in the small intestine, lung, kidney, tonsil, liver, thymus, spleen, brain or mesenteric lymph nodes.

\section{Discussion}

The present study evaluated the results of BVDV infection in sows during gestation after experimental oronasal inoculation with the BVDV-2 CP strain (SV253) bovine isolate. Knowledge of pestivirus diversity is important for control programs and for determining probable sources of infection. Furthermore, a high frequency of BVDV-2 in Brazil compared to other countries was observed and suggested that a BVDV control program based only on investigations of bovines will not be successful in regions where the farms harbor multiple animal species. The presence of sheep was significantly associated with BVDV infection, (Weber et al., 2014); however, there are few studies and data regarding a potential pathogenicity of BVDV in swine.

The BVDV genotype 2 (CP) strain SV253 bovine isolate was used in this study because previous studies have described its ability to infect pigs; this characteristic was desired to justify the need to evaluate infection during the stages of swine gestation (Walz et al., 2004). The overall seroconversion of the three groups was 20 days, with titers ranging from 10 to 160 . In other work with experimental inoculation with BVDV genotype 2 (NCP) SV260, bovine isolate, all gilts were seroconverted for two to three weeks, with anti-BVDV-2 antibody titers ranging from 20 to 40 (Mechler et al., 2018). Experimental infection of eight-week-old pigs with either BVDV-1 or BVDV-2 did not result in clinical signs or increases in body temperature in any group, despite the use of a BVDV 2 isolate that was demonstrated to be virulent for cattle (Walz et al., 1999). In a previous study in which sows were inoculated with BVDV-1 NCP at 65 days of pregnancy, seroconversion was noted at 21 days post inoculation, and titers varied from 64 to 512 (Walz et al., 2004). The degree of infection varies and depends mainly on contact with cattle, age of pigs and degree of homology of virus strains used for serology, with field strains of BVDV infecting pigs (Liess and Moennig, 1990).

The results of the hemogram showed thrombocytopenia, and similar results were obtained by Makoschey et al. (2002), who inoculated BVDV-2 containing NCP and CP biotypes in six-week-old pigs, resulting in mild leukopenia and thrombocytopenia. Some BVDV-2 strains have been reported to be highly virulent and able to cause severe thrombocytopenia and associated hemorrhage in bovine (Corapi et al., 1989). These results suggest that BVDV infection may be associated with a decreased platelet count as described by Corapi et al. (1989). In this study, there was an increase in lymphocyte count in the days following

Table 2

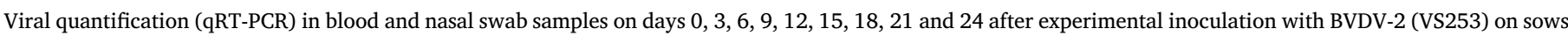
with -30 (G0), 30 (G1), 60 (G2), 90 (G3) days of gestation and a control group (G4).

\begin{tabular}{|c|c|c|c|c|c|c|c|c|c|}
\hline \multirow[t]{2}{*}{ Group } & \multicolumn{9}{|c|}{ Day } \\
\hline & 0 & 3 & 6 & 9 & 12 & 15 & 18 & 21 & 24 \\
\hline 323 (G0) & - & - & $\begin{array}{l}490 \mathrm{TCID}_{50} \\
\text { /ml (VE) }\end{array}$ & - & - & - & - & - & - \\
\hline 392 (G0) & - & - & - & - & $\begin{array}{l}165 \mathrm{TCID}_{50} \\
/ \mathrm{ml}(\mathrm{V})\end{array}$ & - & - & - & $\begin{array}{l}174 \mathrm{TCID}_{50} \\
/ \mathrm{ml}(\mathrm{VE})\end{array}$ \\
\hline 427 (G1) & - & $\begin{array}{l}213 \mathrm{TCID}_{50} \\
/ \mathrm{ml}(\mathrm{V})\end{array}$ & & - & - & - & - & - & - \\
\hline 355 (G1) & - & - & $\begin{array}{l}120 \mathrm{TCID}_{50} \\
/ \mathrm{ml}(\mathrm{VE})\end{array}$ & - & - & - & - & - & - \\
\hline $1386(\mathrm{G} 2)$ & - & - & - & - & $214 \mathrm{TCID}_{50} / \mathrm{ml}(\mathrm{VE})$ & - & - & - & - \\
\hline $364(\mathrm{G} 2)$ & - & - & - & - & - & - & - & - & - \\
\hline 729 (G2) & - & $\begin{array}{l}151 \mathrm{TCID}_{50} \\
/ \mathrm{ml}(\mathrm{V})\end{array}$ & $\begin{array}{l}275 \mathrm{TCID}_{50} \\
/ \mathrm{ml}(\mathrm{V})\end{array}$ & - & - & - & - & - & - \\
\hline 348 (G3) & - & - & - & $\begin{array}{l}107 \mathrm{TCID}_{50} \\
/ \mathrm{ml}(\mathrm{V})\end{array}$ & - & - & - & - & - \\
\hline 365 (G3) & - & - & - & - & - & - & - & - & - \\
\hline 363 (G3) & - & - & - & - & - & - & - & - & - \\
\hline 301 (G4) & - & - & - & - & - & - & - & - & - \\
\hline 347 (G4) & - & - & - & - & - & - & - & - & - \\
\hline
\end{tabular}

V - viremia; VE - viral excretion. 
Table 3

Clinical assessment of fetuses and reproductive losses from BVDV-infected gilts.

\begin{tabular}{lllll}
\hline Groups & Litter zise & Description & $\begin{array}{l}\text { VN Titres in } \\
\text { fetuses }\end{array}$ & $\begin{array}{l}\text { RNA viral in } \\
\text { fetuses }\end{array}$ \\
\hline $323(\mathrm{G} 0)$ & $\mathrm{N}=1$ & Abortion & - & - \\
392 (G0) & $\mathrm{N}=8$ & Stillborn & - & - \\
427 (G1) & $\mathrm{N}=14$ & Normal & - & - \\
$355(\mathrm{G} 1)$ & $\mathrm{N}=10$ & Stillborn & - & - \\
1386 (G2) & $\mathrm{N}=7$ & Normal & - & - \\
364 (G2) & $\mathrm{N}=0$ & Fetal resorption & - & - \\
729 (G2) & $\mathrm{N}=12$ & Stillborn & - & - \\
348 (G3) & $\mathrm{N}=13$ & Normal & - & - \\
365 (G3) & $\mathrm{N}=16$ & Stillborn & - & - \\
363 (G3) & $\mathrm{N}=12$ & Fetal mummy & - & - \\
301 (G4) & $\mathrm{N}=11$ & Normal & - & - \\
347 (G4) & $\mathrm{N}=10$ & Stillborn & - & \\
\hline
\end{tabular}

infection, likely due to the stimulation of lymphocytes TCD8 +, and a lymphocyte drop occurred on the 12th day after inoculation but remained within the normal range for swine. Infection with species-unspecific pestiviruses causes similar but less significant changes within lymphocyte subpopulations than in infection with species-specific pestiviruses (Rypula, 2003).

Infection with BVDV in swine often occurs without clinical signs (Liess and Moennig, 1990; Makoschey et al., 2002), enabling the virus to silently infect a herd; however, natural infection has also been associated with reproductive disorders, abortion and stillbirths (Paton and Done, 1994; Tao et al., 2013); the birth of weak piglets and fetal mummification have been reported in adult animals (Vannier and Albina, 1999). In this work, gilt 364 (G2) returned to estrus after 42 days of gestation, but no abortions were found, and gilt 323 (G0) (Table 3) aborted a fetus that was negative at time of diagnosis for parvovirus, circovirus and BVDV. BVDV-neutralizing antibodies were not detected in the blood serum of the fetuses of the control or infected groups; these newborn piglets were collected without ingestion of colostrum, which agrees with the results of Mechler et al. (2018), who describe litters from oronasally inoculated gilts against BVDV-2 being born with no viruses and no antibodies. The detection of BVDV through qRT-PCR was only possible in the blood and nasal swab specimens of gilts that were experimentally inoculated, and the RNA of BVDV was not detected in the tissues and blood of piglets born to the control gilts (G4) or infected groups (G0-G3). The results of the histopathology showed that neonates did not present significant lesions, as observed by Mechler et al. (2018); in his experiment, swine fetuses were inoculated by an intrauterine route with a strain of BVDV-2, and histopathologically fetal tissues presented no microscopic changes characteristic of infection.

The calibration curve from the initial viral suspension allowed the estimation of virus quantification when related to the Cq of the samples. The number of viral TCID50 in the blood and nasal swab specimens ranged from $107 \mathrm{TCID} 50 / \mathrm{ml}$ to $490 \mathrm{TCID} 50 / \mathrm{ml}$, with the highest viral load being quantified in the nasal swab, 490 TCID50/ml in gilt 323 (G0) six days after the experimental inoculation (Table 2). The viral load detected in sows experimentally inoculated with the BVDV-2 viral strain SV253 was low ( $\mathrm{Cq}<35$ ) compared to the amount of the initially inoculated viral suspension of $10^{6.85} \mathrm{TCID} 50 / \mathrm{ml}(\mathrm{Cq}=15,239)$, and this quantification was low compared to that in other similar studies where the amount of APPV detected in samples of semen of boar was detected $2 \times 10^{6} \mathrm{TCID} 50 / \mathrm{ml}$ and $\mathrm{Cq}<27$ (Gatto et al., 2017). Detection of BVDV RNA in serum and blood was possible in swine receiving a dose of $10^{5}$ TCID50 to $10^{7}$ TCID50 of BVDV-1 but was not detected in swine receiving BVDV-2 (Walz et al., 1999). Our study evaluated the inoculation of a dose of $10^{5.5} \mathrm{TCID} 50 / \mathrm{ml}$. In conclusion, the animals developed transient viremia and excreted the virus, but there was no evidence of transplacental transmission because the amount of virus replicating in the sows was not sufficient to cause vertical transmission.
In cattle, during acute infections, viremia and viral excretion are generally transient and cause low titers but, nonetheless, result in vertical transmission (Thurmond, 2005). Previously published studies in pigs with the HoBi-like virus have reported that pigs seroconverted to the HoBi-like type, but viral RNA was not detected in nasal swab samples (Decaro et al., 2012; Schirrmeier et al., 2004), and clinical signs were not observed, leading to low levels of replication of the virus type HoBi; however, it was concluded that the pigs can support the replication of this virus (Bauermann et al., 2015). Other studies described BVDV as inducing viremia within one week and seroconversion occurring within three weeks of experimental inoculation in swine (Stewart et al., 1980; Kulcsár et al., 2001; Makoschey et al., 2002). Experimental inoculation with BVDV-2 CP (SV253) was conducted successfully, and the results showed that the sows demonstrated a transient viremia, as it was detected in blood samples in sows of G0, G1, G2, and G3 ranging from 3 days and 12 days, and nasal excretion was detected in nasal swabs of G0 and G1 sows between 6 and 24 days after viral inoculation. An elevation of the rectal temperature after BVDV inoculation was not detected in most studies despite evidence of viremia and seroconversion (Carbrey et al., 1976; Walz et al., 1999).

Transplacental infection is associated with several factors, such as the gestational age at which infection occurs and the viral strain (Walz et al., 2004). In this work, BVDV-2 infections at different gestational stages were evaluated, and the results confirmed the lack of vertical infection in piglets, which agrees with the results of Walz et al. (2004), who describe inefficient transplacental infection in sows because the virus did not multiply with great intensity in sows; however, these results disagree with those of studies that demonstrated transplacental infection (Paton and Done, 1994; Kulcsár et al., 2001; Terpstra and Wensvoort, 1997). Possible factors that may have contributed to the lack of transplacental infection in spite of a demonstrable viraemia in the pregnant gilts include an inadequate level of viraemia to induce infect placental tissues, the selection of BVDV isolate CP, and the epitheliochorial characteristic of the swine placenta with six layers of tissues, which has a primordial function in uterine protection against pathogens (Salmon et al., 2009).

\section{Conclusion}

All sows inoculated with BVDV-2 $2^{\text {a }}$ (strain VS253 CP) demonstrated seroconversion. Detection of viral RNA occurred in blood and nasal swabs, demonstrating transient infection behavior with a low viral load compared to the quantification of the inoculated initial viral suspension. There was no evidence of transplacental infection in sows inoculated experimentally at 30,60 and 90 days of gestation, since no antibodies or viral RNA was detected in piglets born from infected sows.

\section{Research funding}

This research was funded by FAPESP (São Paulo State Research Support Foundation) through grant numbers (Process: 2015/08531-0; PhD scholarship) and (Process: 2016/21421-2; research support).

\section{Declarations of interest}

None.

\section{Conflict of interest}

None.

\section{Acknowledgements}

We would like to acknowledge the participation of the following researchers: Dr. Fava CD, Biological Institute of São Paulo; Dr. André MR, Laboratory of Immunoparasitology of São Paulo State University; 
"Júlio Mesquita Filho", Campus of Jaboticabal, São Paulo (FCAV); Dr. Mathias LA, Department of Preventive Veterinary Medicine and Animal Reproduction of FCAV; Prof. Dr. Flores EF from UFSM; Dr. Ribeiro CP from the Biological Institute of São Paulo for the inoculum and laboratory tests; and Andrea Medeiros from the Laboratory of Reproductive Viruses of FCAV for assistance with the serological analyses.

\section{References}

Arenhart, S., Silva, L.F., Henzel, A., Ferreira, R., Weiblen, R., Flores, E.F., 2008. Fetal protection against bovine viral diarrhea virus (BVDV) in pregnant cows previously immunized with an experimental attenuated vaccine. Pesq. Vet. Bras. 28, 461-479.

Bauermann, F.V., Falkenberg, S.M., Decaro, N., Flores, E.F., Ridpath, J.F., 2015. Experimental infection of calves, sheep, goats and pigs with HoBi-like viruses by direct inoculation or exposure to persistently infected calves. Vet. Microbiol. 181, 289-293.

Becher, P., Ramirez, R.A., Orlich, M., Rosales, S.C., Konig, M., Schweizer, M., Stalder, H., Schirrmeier, H., Thiel, H.J., 2003. Genetic and antigenic characterization of novel pestivirus genotypes: implications for classification. Virology 311, 96-104.

Cabezón, O., Rosell, R., Sibila, M., Lavín, S., Marco, I., Segalés, J., 2010. Experimental infection of pigs with border disease virus isolated from Pyrenean chamois. J. Vet. Diagn. Invest. 22, 360-365.

Carbrey, E.A., Stewart, W.C., Kresse, J.I., Snyder, M.L., 1976. Natural infection of pigs with bovine viral diarrhea virus and its differential diagnosis from hog cholera. J. Am. Vet. Med. Assoc. 169, 1217-1219.

Corapi, W.V., French, T.W., Dubovi, E.J., 1989. Severe thrombocytopenia in young calves experimentally infected with noncytopathic bovine viral diarrhea virus. J. Virol. 63, 3934-3943.

Decaro, N., Mari, V., Lucente, M.S., Sciarretta, R., Moreno, A., Armenise, C., Losurdo, M., Camero, M., Lorusso, E., Cordioli, P., Buonavoglia, C., 2012. Experimental infection of cattle, sheep and pigs with 'Hobi'-like pestivirus. Vet. Microbiol. 155, 165-171.

Dezen, S., Otonel, R.A.A., Alfieri, A.F., Lunardi, M., Alfieri, A.A., 2013. Bovine viral diarrhea virus (BVDV) infection profile in a high production dairy herd with vaccination program against BVDV. Pesq. Vet. Bras. 33, 141-144.

Gatto, I.R.H., Arruda, P.H., Visek, C.A., Victoria, J.G., Patterson, A.R., Krull, A.C., Schwartz, K.J., Oliveira, L.G., Arruda, B.L., 2017. Detection of atypical porcine pestivirus in semen from commercial boar studs in the United States. Transboundry Emerg. Dis. 65, 339-343.

Houe, H., 1995. Epidemiology of bovine viral diarrhea virus. Vet. Clin. North Am. Food Anim. Pract. 11, 521-547.

Jain, N.C., 1986. Schalm's Veterinary Hematology. Lea \& Febiger, Philadelphia.

Kulcsár, G., Soos, P., Kucsera, L., Glavits, R., Pálfi, V., 2001. Pathogenicity of a bovine viral diarrhoea virus strain in pregnant sows: short communication. Acta Vet. Hung. 49, 117-120.

Liess, B., Moennig, V., 1990. Ruminant pestivirus infection in pig. Rev. Sci. Tech. Int. Office Epizootics 9, 151-161.

Makoschey, B., Liebler-Tenorio, E.M., Biermann, Y.M., Goovaerts, D., Pohlenz, J.F., 2002. Leukopenia and thrombocytopenia in pigs after infection with bovine viral diarrhoea virus-2 (BVDV-2). Dtsch Tierarztl Wochenschr. 109, 225-230.

Mechler, M.L., Dos Santos, G.F., Nascimento, k.A., De Souza-Pollo, A., Pires, F.F.B., Samara, S.I., Pituco, E.M., De Oliveira, L.G., 2018. Congenital tremor in piglets: is bovine viral diarrhea virus an etiological cause? Vet. Microbiol. 220, 107-112.

Oie-World Organization for Animal Health, 2016. Bovine Viral Diarrhea. Manual of
Diagnostic Tests and Vaccines of Terrestrial Animals. pp. 698-710. 2015a Available at. http://www.oie.int/fileadmin/Home/eng/Health_standards/tahm/2.04.07_BVD. pdf Accessed on 04 April 2016.

Paton, D.J., Done, S.H., 1994. Congenital infection of pigs with ruminant-type pestiviruses. J. Comp. Pathol. 111, 151-163.

Pellerin, C., Van den Hurk, J., Lecomte, J., 1994. Identification of a new group of bovine viral diarrhea virus strains associated with severe outbreaks and high mortalities. Virology 203, 260-267.

Postel, A., Hansmann, F., Baechlein, C., Fischer, N., Alawi, M., Grundhoff, A., Derking, S., Tenhündfeld, J., Fankuche, V.P., Herder, V., Baumgärtner, W., Wendt, M., Becher, P., 2016. Presence of atypical porcine pestivirus (APPV) genomes in newborn piglets correlates with congenital tremor. Sci. Rep.-U. K. 6, 1-9.

Ridpath, J.F., 2010. Bovine viral diarrhea virus: global status. Vet. Clin. North Am. Food Anim. Pract. 26, 105-121.

Rypula, K., 2003. The effects of experimental infection with bovine diarrhoea virus (BVDV) on lymphocyte subpopulations in the peripheral blood of pigs. Pol. J. Vet. Sci. 6, 189-193.

Salmon, H., Berri, M., Gerdts, V., Meurens, F., 2009. Humoral and cellular factors of maternal immunity in swine. Dev. Comp. Immunol. 33, 384-393.

Schirrmeier, H., Strebelow, G., Depner, K., Hoffmann, B., Beer, M., 2004. Genetic and antigenic characterization of an atypical pestivirus isolate, a putative member of a novel pestivirus species. J. Gen. Virol. 85, 3647-3652.

Smith, D.B., Meyers, G., Bukh, J., Gould, E.A., Monath, T., Pletnev, A., Rico-Hesse, R., Stapleton, J.T., Simmonds, P., Becher, P., 2017. Proposed revision to the taxonomy of the genus Pestivirus, family Flaviviridae. J. Gen. Virol. 98, 2106-2112.

Stewart, W.C., Miller, L.D., Kresse, J.I., Snyder, M.L., 1980. Bovine viral diarrhea infection in pregnant swine. Am. J. Vet. Res. 41, 459-462.

Tao, J., Wang, Y., Wang, J., Wang, J., Zhu, G., 2013. Identification and genetic characterization of new bovine viral diarrhea virus genotype 2 strains in pigs isolated in China. Virus Genes 46, 81-87.

Terpstra, C., Wensvoort, G., 1997. A congenital persistent infection of bovine virus diarrhoea virus in pigs: clinical, virology and immunology observation. Vet. Q. 19, 97-101.

Thurmond, M.C., 2005. Virus transmission. In: Goyal, S.M., Ridpath, J.F. (Eds.), Bovine Viral Diarrhea Virus: Diagnosis, Management and Control. Blackwell Publishing, Oxford, UK, pp. 91-104.

Vannier, P., Albina, E., 1999. Bovine viral diarrhea and border disease. In: Be, Straw, D'Allaire, S., Wl, Mengeling, Taylor, Dj (Eds.), Diseases of Swine. Blackwell Science, Ames.

Viet, A.F., Fourichon, C., Seegers, H., 2007. Review and critical discussion of assumptions and modeling options to study the spread of the bovine viral diarrhea virus (BVDV) within a cattle herd. Epidemiol. Infect. 135, 706-721.

Vilcek, S., Durkovic, B., Kolesarova, M., Greiser-Wilke, I., Paton, D.J., 2004. Genetic diversity of international bovine viral diarrhoea virus (BVDV) isolates: identification of a new BVDV-1 genetic group. Vet. Res. 35, 609-615.

Walz, P.H., Baker, J.C., Mullaney, T.P., Kaneene, J.B., Roger, K., Maes, R.K., 1999. Comparison of type I and type II bovine viral diarrhea virus infection in swine. Can. J. Vet. Res. 63, 119-123.

Walz, P.H., Baker, J.C., Mullaney, T.P., Maes, R.K., 2004. Experimental inoculation of pregnant swine with type 1 bovine viral diarrhoea virus. J. Vet. Med. 51, 191-193.

Weber, M.N., Silveira, S., Machado, G., Groff, F.H.S., Mósena, A.C.S., Budaszewski, R.F., Dupont, P.M., Corbellini, L.G., Canal, C.W., 2014. High frequency of bovine viral diarrhea virus type 2 in Southern Brazil. Virus Res. 191, 117-124.

Zeitler, B., Rapp, I., 2013. Determination of infectious bovine viral diarrhea virus in bovine lung lavages by a combination of virus propagation in cell culture and quantitative real time PCR. IRNS Virol. 49, 1-9. 